\title{
Machine Application at The University of Hawaii
}

R EGretably it is NEcessary to set the record straight about the experiment in computer charging at the University of Hawaii. The article purporting to deal with this topic in the May 1965 issue of CRL does not present an accurate account. It treats of many topics and of possible routines that have no relationship with the system actually installed and tested at the University of Hawaii, and if left uncorrected the article will seriously mislead the profession.

This reply is limited to the minimum areas that must be discussed if the erroneous impression given by the article is to be corrected. These are: (1) accuracy of the statements in the article; (2) operational efficiency of the system actually installed and tested; (3) program efficiency of the system actually installed and tested; and (4) outcome of the test.

1. With regard to the accuracy of the factual statements in the article, I shall limit 'my discussion to the statements in just one column, even though many other statements are equally questionable.

Taking the right hand column of page 217 , the first sentence states, "The automation of the order department routines is already flow-charted and approved." Fact: If the operations have actually been flow-charted the head of the Sinclair library, the head of the order department and the head of the cataloging department have no knowledge of the alleged flow-charts, and it can be stated

Dr. Shaw is Dean of Library Activities in the University of Hawaii. with certainty that no system for this purpose has been submitted for consideration, let alone being approved, and its implementation date is not being delayed by personnel vacancies.

The second sentence in the next paragraph says, "It was designed to operate at approximately the same cost as the unsatisfactory manual system which preceded it ..." Fact: The cost was more than twice as high as that for the system it succeeded. See part 2.

The next sentence says, "A $\$ 25,000$ switchover budget was approved and at this writing it appears that a large portion of this amount will be returned to the state at the end of the fiscal year." Fact: There is no basis for this statement as indicated by the facts in part 2, which were available early in April.

The next sentence says, "Machine costs turned out to be considerably lower than expected as a result of unpredictable advantages gained through cooperative use of certain items." Fact: There was no cooperative use of any of the items rented by the library, and during the period of the test they were used for nothing other than circulation. Computer costs at the Computer Center were double the preliminary estimate.

There are many other statements and allegations in this article that are definitely open to question, but it does not seem necessary to pursue this further.

2. Operational efficiency. Using the costs for October through March, and projecting the costs for the year at the March rate when the costs were slightly lower because the debugging had pre- 
sumably been completed, the annual cost of computer charging for salaries, machine rental and supplies in the library was $\$ 86,498.52$ plus cost of computer time of $\$ 33,000.00$, or a total of $\$ 119,498.52$ per year. The cost of the system that the computer charging replaced was $\$ 53,027.73$ per year. These figures are based on actual payroll records for both periods, supplies and rentals shown on the university books, and time billed by the Computer Center. There were no activities added at the circulation desk during the period 1964/ 65 , so the net cost of computer charging was found to be substantially more than double that of the old manual charging system, which was no model of efficiency.

3. Program efficiency. The chief objection to the old charging system, as stated in the Black report, which the May article alleges to be the basis for the change, was, "Indeed the present circulation system is under attack solely because of the difficulty of ascertaining where books may be if they are not on the shelves." This objection was based on the fact that it was, in the old system, necessary to consult multiple files and that it sometimes took from fifteen to thirty minutes to locate a book. Under the computer charging system as installed at Hawaii, it was always a day before the charge got into the files since the computer was run once a day only, and book charges from Friday afternoon at 4 PM through Monday at 4 PM did not become available until Tuesday morning. In fact the log kept of date of charge and date when the computer charge record became available to the circulation desk shows that the mean time for getting a charge into the computer file was 3.3 days, and that on several occasions the delay ran two weeks or more before the location of a book could be determined.

Overdues, which sound real tidy in the May 1965 article, were in fact re- ported to the library only twice between the time computer charging actually started on October 8, 1964, and March 31 , which made a farce of the time control system. Overdues could not be sent even after the overdue printouts were received because they were so far out of date.

While renewals, as stated in the article, can be handled by running the book card back through the machine, the article fails to point out that this requires that the book be brought back to the library to make the machine-readable book card available. An alternative would be to repunch the book card. This would be difficult with information obtained over the telephone and would require the punching of three cards which would then be sent to the Computer Center and would be converted into one book card and returned a week later after which the renewal could be run into the system. The net result is that renewals could only be handled if the borrowers brought the books back instead of their being handled by telephone.

Another major factor in terms of program efficiency is the fact that one-day loans or reserve-book loans could not be handled in the computer charging system as designed and operated, which meant that more than half the charging continued to be done manually as before, resulting in multiple charging systems in use at the same time.

4. Outcome of the test. After the data noted above and other results of the test were studied by everyone concerned, the rental of the equipment was cancelled as of May 6, 1965, and a simple charging system using an IBM 026 punch for about four hours per week and a tabulator at the Computer Center for about two hours per week was put into operation on June 1, 1965. This system uses a uniform method for all materials charged and provides time control and (Continued on page 398) 
a key to the library on assumption of responsibility for the collection during that period of time. Cooperation between the individual scientists, the departments, and the library in collecting material is essential. As individual collections increase to an unmanageable size, they should cumulate into departmental reading rooms, and when these reach a critical size the collections should fade into control and supervision by the library. The location of science collections, departmental or library owned, should be as central as possible to all departmental laboratories and connected by passageways if necessary. An ideal solution to this problem would seem to be the following description of a sciences building complex:

. . . a great wheel, or pentagon, in which the science library would be the hub, the radiating spokes the major disciplinesphysics, mathematics, chemistry, the biological sciences-and the rims the laboratories."

Finally, if the library's users include students, a strong argument can be made for centralizing science collections for their convenience. They will be taking courses in a variety of subjects, and in an era when ever-increasing quantities of materials must be covered in each subject any time saved for students would be an educational advantage.

In conclusion it should be stressed that a university or college library's main function is to provide the user with those books that have a frequency of use that is so low, or a cost that is so high, as to prohibit individual purchase or ownership and to increase the educational value of each item by adding to the completeness of the collection. Within those sciences that need to use books and journals in a laboratory situation it is necessary that individual scientists and departments assume ownership and responsibility for some types of library materials.

\footnotetext{
8 Shera, op. cit., p. 42.
}

\section{University of Hawaii}

(Continued from page 382 )

location of materials charged within five minutes at most. Three professional positions have been transferred from the circulation department to other places where they are needed. Two of these positions were filled and the personnel are now working in other departments, the third is in process of being filled in another department.

Caveat: This is not a generalization about computer charging. It is a factual report on the system as it was actually applied at the University of Hawaii. It may very well be that some system still to come and some machine configuration still to come may give us better control of loans for less money, but that remains for the future.

This is not a condemnation of the use of computers in libraries when suitable. We have, in fact, just completed the systems work and programing, including two dry runs, and have converted to computer handling of our accounting records for book purchases, which have to be distributed against some fifty accounts. The time studies on this application indicate that the use of a key punch for two hours per day plus the use of a 1401 computer for not more than ten minutes per month will save us a net of somewhat more than fourman-years while giving us better and more prompt control of our book expenditures. As fast as we can develop, or anyone can show us, other applications that will in fact release time for library services or money for books we will put them into operation. This, however, requires rigorous systems work and careful costing so that we can be reasonably certain that the change will result in an improvement. The kind of reliable and helpful information that is needed is not provided by articles such as the one under discussion. 